\title{
The folic acid and folates content in fortified fruit juices
}

\author{
Marta Czarnowska-Kujawska, Elzbieta Gujska, Joanna Michalak and Dominika Leończuk \\ Department of Food Science, University of Warmia and Mazury, Olsztyn, Poland
}

\begin{abstract}
Introduction: Folates are water-soluble vitamins of the great nutritional importance. Their deficiencyin the diet is common worldwide. Most people do not obtain sufficient folate amount in their diet by eating fresh vegetables, fruit, beans or whole grains. More and more products available on the market are fortified with the synthetic folic acid. Since the consequences of an excessive intake of this vitamin for the organism are not fully explained, there is a need to know its real contents in fortified products. Fruit juices fortified with folic acid can also be a good source of naturally occurring derivatives, folates. Folates, however, as a very unstable nutrient, may be degraded during the production process and storing to the form which has no biological function. Thus, it is crucial to have an appropriate information on the stability of folic acid and folates in fortified products and their retention during storage.
\end{abstract}

Objectives: The objective of this study was to quantify the total folic acid and folates content in fruit juices affected by the time of storage at room temperature. This will help to better understand the potential health value of fortified fruit juices.

Material and Methods: Five fortified fruit juices with the declared on the packaging folic acid content in the amount of $30 \mu \mathrm{g} / 100 \mathrm{ml}$, were purchased at local supermarkets. Folic acid and folates were extracted in the $0.1 \mathrm{M}$ phosphate buffer $(\mathrm{pH}=7.0)$, followed by deconjugation with conjugase (rat plasma) and separated by HPLC after clean-up using SAX SPE cartridges.

Results: Folic acid content $(90-140 \mu \mathrm{g} / 100 \mathrm{ml})$ significantly exceeded the value declared by the manufacturer. $\mathrm{The}^{5} \mathrm{CH}_{3} \mathrm{FH}_{4}$ form in juices was found at the trace amounts. In two tested juices this content was 3.46 and $3.41 \mu \mathrm{g} / 100 \mathrm{ml}$. After seven months of storage folic acid content significantly decreased even $2-3$ times $(38-67 \mu \mathrm{g} / 100 \mathrm{ml})$ but these values were still higher than the value declared by the manufacturers. The $5 \mathrm{CH}_{3} \mathrm{FH}_{4}$ form content after storing was determined at a trace amounts.

The conducted research allowed to confirm that producers deliberately use "technological surpluses" for juices in order to minimize possible losses that may occur during the production process as well as during storage. Based on the obtained results, it can be concluded that the tested fruit juices can be a valuable source of folic acid. However, it should be considered whether their excessive amount will not have negative effects, instead of contributing to the prevention of many diseases.

\section{Conflict of Interest}

There is no conflict of interest 